\title{
Modification in Power Transmission System by Providing Effective and Easy Power Engaging and Disengaging System in Multi-Purpose Power Unit
}

\author{
Rahul Gautam $^{1 *}$, Avinash Gautam ${ }^{1}$, Nimbalkar Dattatray ${ }^{2}$ and Nandni Thakur ${ }^{3}$ \\ ${ }^{1}$ CRP on FM-PF, ${ }^{2}$ AICRP on UAE, ${ }^{3}$ AICRP on ESA, ICAR-Central Institute of Agricultural \\ Engineering, Bhopal-462038, Madhya Pradesh, India \\ *Corresponding author
}

A B S T R A C T

Keywords

Power unit, V-belt, Gear etc.

\section{Article Info}

Accepted:

24 August 2018

Available Online:

10 September 2018
A self-propelled multipurpose power unit was developed in the laboratory of Farm Machinery and Power Engineering, JNKVV, Jabalpur for small farmers. The prime mower is powered by $5 \mathrm{hp}$ diesel engine. V-belt drive is provided for transmission of power from the engine to the traction wheels. An adjustable accelerator wire is connected to the governor for adjusting the engine speed according to the requirement. The worm gear reduction unit is located at the axle having speed reduction ratio of 20:1. A telescopic type frame is provided to support the end of adjustable output shaft with the help of bearing. The handle is modified so as to vary the height from 1.0 to $1.3 \mathrm{~m}$ from the ground. The addition lug cage wheel is connected to transport wheel to increase the traction. This resulted into less effort better contact and less than 2\% slippage between belt and pulley. Now the working of power engaging system is working with an ease.

\section{Introduction}

The presence of a large number of marginal and small land holdings farmers (80\%) [5] In India approves the importance of power tiller as the most suitable farm power source for field operations, in view of its compact size, low cost and versatility. Power tiller is a walking type small tractor used for agricultural operations in most part of the world. It is mainly used for field preparation sowing and other operations like Inter-culture, mower \& harvesting in small agricultural fields. This power unit has gained popularity among farmers due to its rugged and reliable operation. The small holding farmers faced many problems including poor access to modern inputs and credit, poor infrastructure, inadequate access to markets, land and environmental degradation, and inadequate research and extension services. A study about the use of Power Tiller among small farms indicated that there was $70 \%$ increase [6] in yield. The suitability of these small prime movers can further be increased to the greater extent, if it turns out to be suitable for some 
left out field operations like water lifting, winnowing, cleaning \& grading operation then this unit may become the complete selfpropelled multipurpose unit. In general the available power units are developed for a specific kind of work so small and marginal farmers may not be able to purchase different machines for different operations. The solution for such problem can be provided by the development of small multipurpose power unit that may be worthwhile endeavor in this context. This unit must be able to perform the most field operations from tillage to post harvest operations. The availability of multipurpose power unit with the marginal and small farmers may avoid the year round maintenance of bullocks and also the high investment in tractors. This machine must be simple in design and can be fabricated \& repaired by village artisans. The structure of power unit must be so simple so it provided better maneuverability and better floatation for kharif crops. The present study will be carried out for modification of following objective by providing effective and easy power engaging $\&$ disengaging system and Modification to achieve better traction and operation comfort.

\section{Design consideration of power unit}

\section{Engine}

Engine is main power sources for the power unit.

Power $=5 \mathrm{hp}$;

Speed $(\mathrm{n})=1200 \mathrm{rpm}$.

Calculate torque on engine output shaft

$$
\mathrm{hp}=\frac{\frac{\mathrm{mn} \mathrm{MT}}{4600}}{400}
$$

Where,

$\mathrm{hp}=$ Horse power;

$\mathrm{N}=$ rpm; and
$\mathrm{T}=$ Torque $(\mathrm{kg} \mathrm{cm})$.

$\mathrm{T}=\frac{\operatorname{sx} 42500}{\mathrm{z} \times \mathrm{m} \times 17000}=2.98 \mathrm{~kg} \mathrm{~cm}$

Design of power transmission from prime mover to wheel

A 5HP engine with $1200 \mathrm{rpm}$ has been taken. The required rpm of feed shaft is $18 \mathrm{rpm}$ (assumed).

Therefore to reduce the rpm, drive pulley is replaced with larger diameter pulley and decrease the diameter of traction wheel. The size of driven pulley and traction wheel is decided by calculation as given below.

$\mathrm{Ne} \times \mathrm{De}=\mathrm{Np} \times \mathrm{Dp}(\mathrm{eq} 1)$

Where,

$\mathrm{Ne}=$ no. of revolution per minute of pulley of engine;

$\mathrm{Np}=$ no. of revolution per minute of pulley of transmission system;

De $=$ dia. of pulley of engine $\mathrm{cm}$; and

$\mathrm{Dp}=$ dia. of pulley of transmission system, $\mathrm{cm}$.

$1200 \times 10=\mathrm{Np} \times 30$

$\mathrm{Np}=400 \mathrm{rpm}$

Since speed ratio $=20: 1$

No. of revolution of traction wheel $(\mathrm{N})=20$ rpm

The forward speed of power unit was calculated as:

Forward speed $S=\frac{\pi \text { elless }}{2000}($ eq2)

Where, 
$\mathrm{S}=$ speed of power unit, $\mathrm{km} / \mathrm{h}$;

$\mathrm{D}=$ diameter of traction wheel, $\mathrm{m}$; and

Diameter of traction wheel $=640 \mathrm{~mm}$.

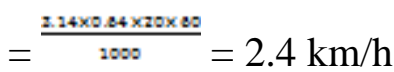

Consider $10 \%$ slip, and then speed will be $2.16 \mathrm{~km} / \mathrm{h}$.

Calculate drawbar horse power (DBHP)

BHP of engine $=5 \mathrm{hp}$

$\mathrm{DBHP}=80 \%$ of BHP

$\mathrm{DBHP}=0.80 \times 5=4 \mathrm{hp}$

Calculate drawbar pull

Speed will be $2.46 \mathrm{~km} / \mathrm{h}$.

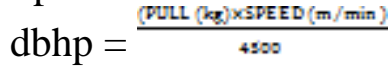

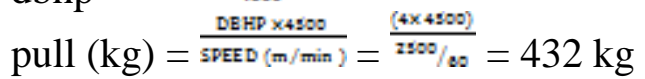

Length of open belt

Length of open belt is calculated as

$=\pi \frac{\left[\mathrm{D} z+\mathrm{D}_{\mathrm{D}}\right]}{\mathrm{z}}+\frac{\left(\mathrm{D} z-\mathrm{D}_{\mathrm{p}}\right]^{2}}{4 \mathrm{z}}+2 \mathrm{C}(\mathrm{eq} 3)$

Where,

$c=$ distance between center of two pulley $=36$

$\mathrm{cm}$

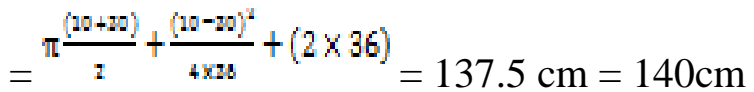

Thus a V belt of B140 is selection for transmission of power.

Determination of diameter of axle:

The axle is a rotating member which transmits power from one point to another point.

Power $=5 \mathrm{hp}$;
Rpm of the axle $=20 ;$ and

Maximum permissible shear stress $=600$ $\mathrm{kg} / \mathrm{cm} 2$.

$\mathrm{hp}=\frac{\frac{\mathrm{zn} \mathrm{NT}}{4050}}{450}$

Where,

$\mathrm{hp}=$ Horse power;

$\mathrm{N}=$ rev. per minute; and

$\mathrm{T}=$ torque in $\mathrm{kg} \mathrm{cm}$.

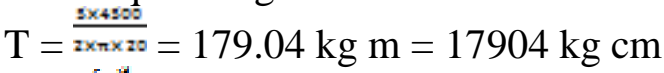

$\mathrm{T}=\frac{\mathrm{nF} \mathrm{F}_{\mathrm{x}}}{20}$

Where,

$\mathrm{T}=$ torque;

fs $=$ max. permissible shear stress; and

$\mathrm{d}=$ dia-meter of axle.

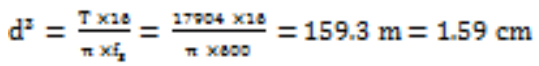

$\mathrm{d}=2 \mathrm{~cm}$

Selection of V - belt and pulley

$\mathrm{V}$ belt drive has been selected for the design as it has following advantageous features.

Noiseless and quiet running.

No lubrication.

Acts as cushions shock.

Alignment requirements are less critical.

The v-belt drive, by slippage overcome the over loads and thus acts as a safety too.

If required, direction of shaft rotation can be easily reversed by crossing the belts.

The speed reduction is provided in three stages. In first stage engine speed reduction from 3000 to $1200 \mathrm{rpm}$ by a built-in spur gear. 
In second stage reduction is done by means of v-belt drive between engine output shaft and gearbox input shaft and in the third stage engine gears are used to reduction speed to 20:1 gears ratio.

\section{Selection of bearings}

When there is a relative motion between two machine parts, one of which supports the other, the supporting member is called bearing. Bering plays important role in working of machine. A bearing helps a machine in many ways viz. carrying and distribution load, reduction friction to minimum, safeguard revolving, oscillating or reciprocating parts from wear due to friction etc. It helps in assembly of two parts from wear due to friction. Apart from providing support the bearing reduces friction between the moving parts, which would otherwise cause a loss of available power. Selection of bearing for farm machines is made with the following requirements.

Self - alignment often required dare to high deflections of light weight construction.

\section{Materials and Methods}

The present self-propelled power unit was initially developed as power weeder for intercultural operation and later on it was further developed as multipurpose Power unit to perform secondary tillage and sowing operation. The machine is sequentially modified to full fill the need of small and medium farmers for different field operations. Show in figure 1.

\section{Fabrication and installation of power drive system}

The self-propelled unit comprises of 5hp diesel engine, speed reduction unit (gear box) and $\mathrm{V}$ - belt pulley arrangement. These are arranged as to keep the machine balanced. The worm type gear reduction unit was located at the axle having gear reduction ratio of 20:1. The speed reduction was done in 2 stages. First stage gave reduction of engine speed from 1200 to $400 \mathrm{rpm}$ with the help of $\mathrm{v}$ belt pulley. The bigger pulley fitted at the end of gear box input shaft and smaller pulley fitted on output shaft of the engine. The dia. of corresponding pulleys are $30 \mathrm{~cm}$ and $10 \mathrm{~cm}$ respectively. These pulleys were connected to a V-belt of size B 46. Second stage reduction was in the worm gear reduction unit. The output shaft of gear was extended in both sides and used as the axle for the traction wheels. Two V-pulleys, one V-belt and two idler pulley linkage system was used to transmit the power from engine to the traction wheels. One U clamp of flat mild steel was fabricated and arranged in such a manner so that it could move on driven idler pulley touching its surface of the V-belt. It was used for increases the angle of contact on the idler pulley and maintains the desired tension as the belt stretches for engaging and disengaging power transmission unit. The detail construction of clutch system is given in figure 2 . The outer linkage flat iron of size made of MS angle $40 \times 4 \mathrm{~mm}$ according to width and thick are used. The vertical bar was connected to horizontal bar with the help of nut and bolts and fixed on frame. The clutch lever was made of $20 \mathrm{~mm}$ dia. and $50 \mathrm{~cm}$ length. Clutch lever was fitted along with the help of spring. Under the normal condition, both idler remained in engaging position due to spring pressure and the power transmission through from driven pulley to tight the belt and rotation of one causes rotation of the other output shaft of the gear reduction unit. When the clutch handle was push down, the u clamp at the engaged idler with belt and disengaged the power supplied from engine output shaft. The linkage clutch was brought back to the engaged position by bringing back the handle to its normal position (Fig. 3). 


\section{Results and Discussion}

This chapter deals with the study related to modification of existing self-propelled multipurpose power unit machine and the performance evaluation of developed output rotary shaft to operate various machinery and provide attachment of tillage tool bar for tillage operation under laboratory and actual field condition. It also contains the cost economics. The utility of the same machine may vary with the land holding. The machine can be used for 1000 to 1500 hour per year. A larger farmer can handle larger area. This small walking type tractor costing low may equally usable to the large farmers as they also possess different practices of small land in different location in the village (Table 1).

Fig.1 Self propelled multipurpose power unit

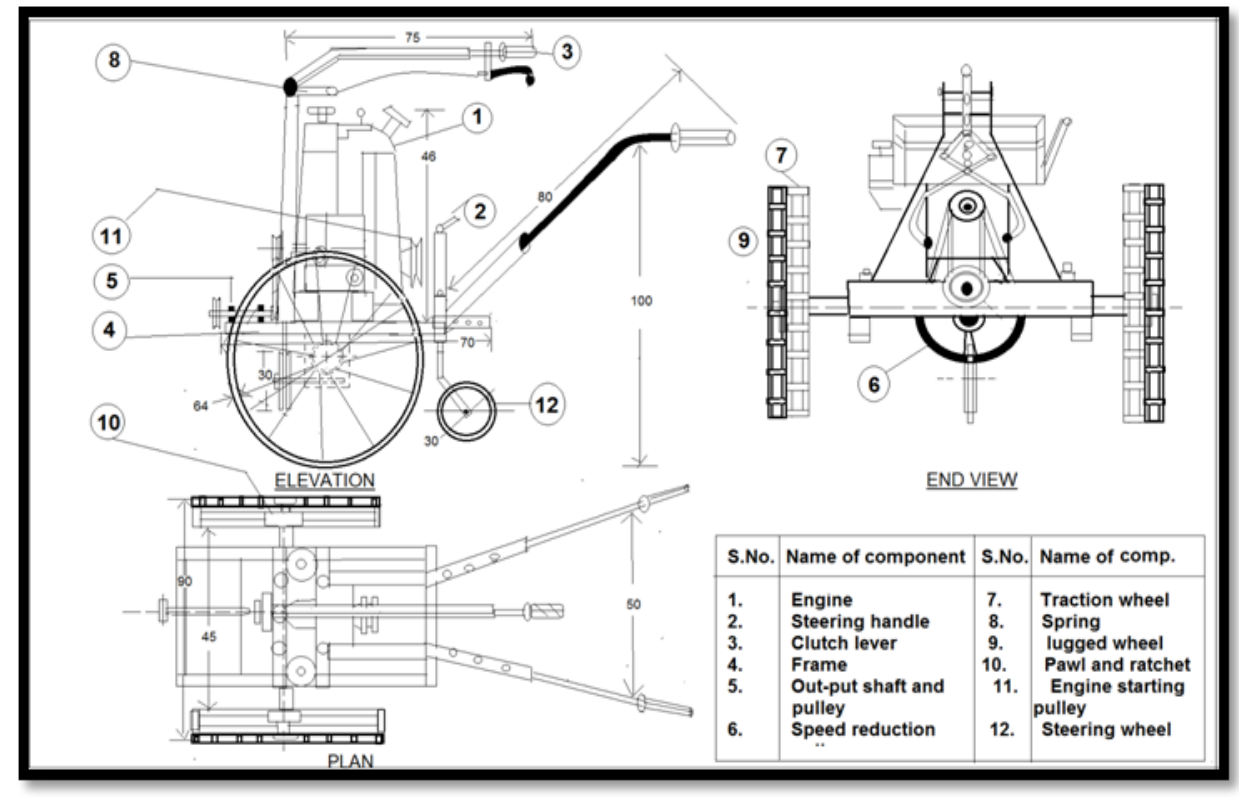

Fig.2 Line daigram of power engaging and disengaging system

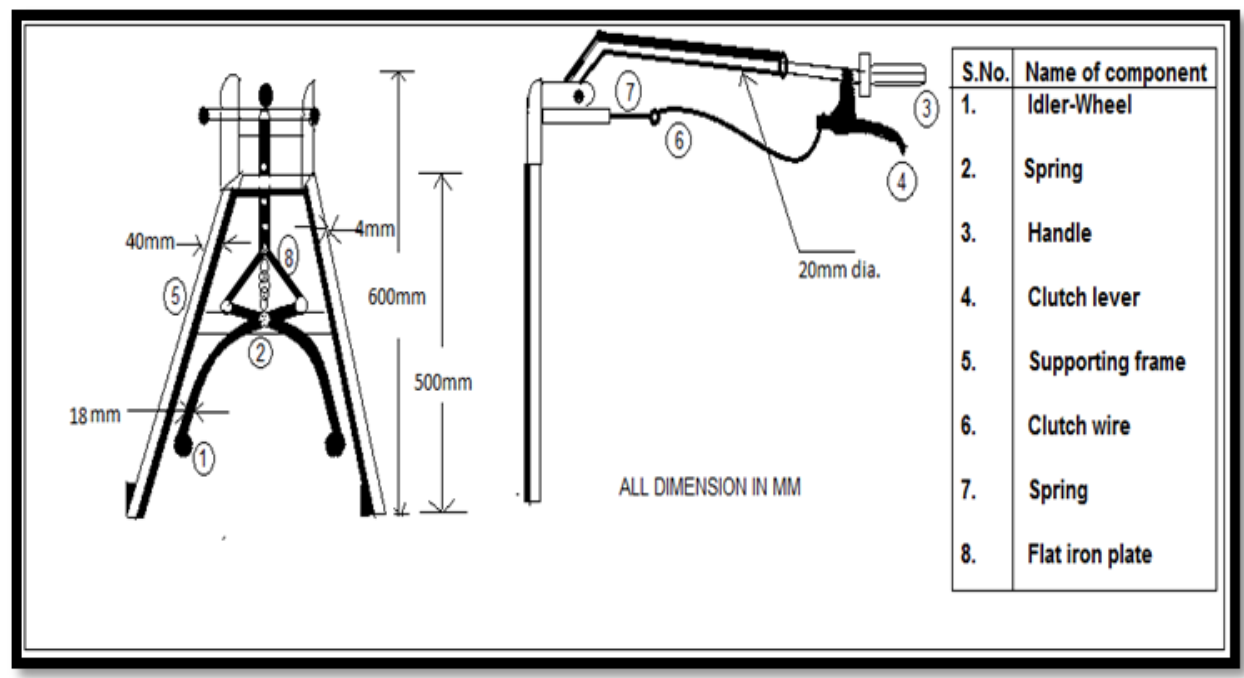


Fig.3 Arrangement of power engaging and disengaging (A) existing (B) modified

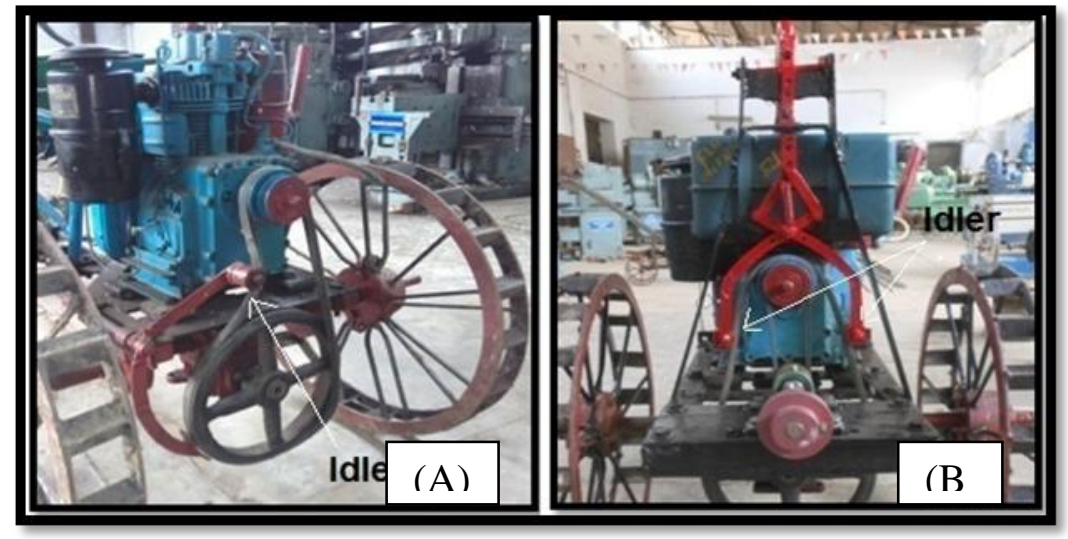

Table.1 General specification of multipurpose power unit

1. Type

2. Over all dimensions

a) Length $(\mathrm{mm})$

b) Width $(\mathrm{mm})$

c) Height $(\mathrm{mm})$

d) Weight $(\mathrm{kg})$

3. Dimension of frame

4. Ground clearance $(\mathrm{mm})$

5. Engine

\section{Wheel}

7. Output shaft
: $\quad$ walking type with two traction wheels

: $\quad 1500$

: 820

: $\quad 1000$

: 106

: $\quad$ made of MS angle $50 \times 50 \times 5 \mathrm{~mm}$

: $\quad 450$

: $\quad 5 \mathrm{hp}$ air cooled diesel engine lambordani

\section{Greaves}

: $\quad 640 \mathrm{~mm}$ dia. angle iron transport wheel

: $\quad$ Mild steel Length $-300 \mathrm{~mm}$ Dia. - $20 \mathrm{~mm}$

\section{Power engage and disengage system}

The power from engine output shaft is transmitted to input shaft of gear reduction unit through belt. In existing power unit single idler pulley was mounted on the frame which moved a lever up and down by cable and bar to tight and slack the v-belt on pulley. There was the friction between belt and pulley resulting to high temperature and sticking of belt due to release problem. This system did not work effectively and when it was disengaged by lever power transmission was not completely disconnected. To eliminate this problem modified power transmission system was developed and the system engage and disengage become easy due to reduction in quantity of linkages resulted into less effort and more contact area cause reduction of slippage and heat generation in the belt. Now this system is working proper with less effort. Two idler pulley are used which resulted in to more contact area thus less heat generation between belt and pulley. The Power transmission system was developed and the system engage and disengage become easy due to reduction in number of linkages. This resulted into less effort better contact and less than $2 \%$ slippage between belt and pulley. Now the working of power engaging system 
is working with an ease. Two idler pulley are used in clutch system which resulted in to more contact area and the problem of slippage is solved completely. The use of scissor like linkage to engage and disengage the idler pulley is found very effective and response immediately for connecting and disconnecting the belt with idler pulley.

On the basis of above it can be concluded that the 5hp self-propelled power unit developed under the project is a low cost power unit which can efficiently be used for various tractive and stationary work and such power unit is found to be most useful prime mover for small and medium farmers. Due to the change of power engaging system and reduction of linkages reduced the operator's drudgery.

\section{References}

Ademiluyi S.Y. and Oladele O.L. (2008) Field performance of VST Shakti power tiller on sawah rice plots in Nigeria and Ghana. Bulgarian Journal of Agricultural Science, 14 (No.5):517522.

Anonymous (2002) Developed of light weight weight power tiller in P.A.U. Annual report of all Indian coordinate scheme on FIM. http://www.icar.org.in/ files/icar 2001.pdf.
Anonymous (2002) Development of selfpropelled interculture equipment in C.I.A.E. Bhopal. Technical bulletin no. C.I.A.E/7/8/3.

Ghaddge S.V., Satapathy K.K., Singh R.K.P. (2000). Prospects of light weight power tiller in the northeastern region of India. Vol. 24(6): 42-48.

ISO 9935, (2002). Power Tiller-Test Code. Bureau of Indian Standards Manak bhavan, New Delhi. https://law. resource.org/pub/in/bis/S06/is.9935.200 2.pdf.

Kadam RG and Dhande KG, (2016). Performance Evaluation of Power Operated Paddy Winnower. Vol 9. (1): $47-52$.

Narang S. and Tiwari P.S. (2005). Performance studies on selected light weight power tillers. Journal of Agricultural Engineering, Vol. 42(3):23 p.

Swapnil Kadu L., Ganesh Kadam B., Kishor Jadhav P., Vikas Gawade S., Abhijit Garje and Anil Gosavi (2015). Design, Development and Operation of 3.5HP Power Tiller, Vol. 2(1):149-154.

Veerangouda M., Sushilendra E.R. and Anantachar M. (2011).Development and Evaluation of Multipurpose Tool Carrier for Power Tiller. Karnataka J. Agric. Sci., 24 (5): 704-705.

\section{How to cite this article:}

Rahul Gautam, Avinash Gautam, Nimbalkar Dattatray and Nandni Thakur. 2018. Modification in Power Transmission System by Providing Effective and Easy Power Engaging \& Disengaging System in Multi-Purpose Power Unit. Int.J.Curr.Microbiol.App.Sci. 7(09): 35573563. doi: https://doi.org/10.20546/ijcmas.2018.709.441 